\title{
A Recommended Strategic Model to Change the Audit Process of the State Audit Office of Vietnam
}

\author{
Le Anh Minh ${ }^{1,2}$ \\ ${ }^{1}$ Vietnam Meteorological and Hydrological Administration, Vietnam's Ministry of Natural Resources and Environment, Hanoi, Vietnam \\ ${ }^{2}$ Centre of Science Research and Training, State Audit Office of Vietnam, Hanoi, Vietnam
}

\section{Email address:}

leanhminh6868@gmail.com

\section{To cite this article:}

Le Anh Minh. A Recommended Strategic Model to Change the Audit Process of the State Audit Office of Vietnam. International Journal of Business and Economics Research. Vol. 7, No. 4, 2018, pp. 79-87. doi: 10.11648/j.ijber.20180704.11

Received: June 12, 2018; Accepted: July 4, 2018; Published: July 31, 2018

\begin{abstract}
The audit process of the State Audit Office of Vietnam (SAV) has inherent limitations and weaknesses that need to be addressed in order to keep pace with the development of the SAV. This paper aims to improve the SAV to meet international auditing standards of the Organization for Economic Co-operation and Development (OECD). It will use the Australian Government audit process as a direct comparison in order to identify issues in the change management processes required for the SAV and to propose a methodology to resolve these issues. Although research methodology focused on semi-structured indepth individual interviews, document review was used to supplement the overall data. The research findings indicate agreement over previous attempts by the literature review. These findings suggested that the change management process may face various issues arising from personal barriers to the change, the SAV culture, application of technology to auditing, costs for the change, the SAV auditor human resource quality and training, and the SAV organizational and operational model. The proposed strategic framework to resolve these issues addressed removing personal barriers to the change, improving infrastructure, human resource, training and legal framework of the SAV, and implementing changes in the SAV culture. These outcomes may assist the SAV in providing the proposed recommendation for the strategic model to change the audit process of the SAV.
\end{abstract}

Keywords: SAV, OECD, Australia, Audit Process, Auditing Standards

\section{Introduction}

The SAV is a powerful office in Vietnam's political system. As the State Audit Office of Vietnam [1] states, the SAV plays an important role in monitoring and controlling the management and utilization of the funds and assets of all government departments in Vietnam. The State Audit Law 2015 of Vietnam has opened up an important legal framework for developing the SAV and its audit process [2]. The audit process of SAV was promulgated as an important mechanism to introduce and assess how the auditors work and achieve their objectives and tasks [3]. However, this audit process has inherent limitations and weaknesses that need to be addressed in order to keep pace with the development of the State Audit Office of Vietnam. This could be realized if a strategy to change the audit process of SAV to align with, say, the Australian Government audit process was implemented.

\section{Literature Review}

\subsection{Overview of the Current Performance of the SAV}

The audit process of SAV contains inherent limitations and weaknesses which have negative effects on the quality of the Vietnamese public administration. The limitations and weaknesses of the audit process of the SAV are presented in Table 1. 
Table 1. Limitations and weaknesses of the audit process of the SAV.

\begin{tabular}{lll}
\hline & Limitations and weaknesses of the audit process of the SAV & Sources (Examination of documents that have been contributed) \\
\hline 1 & Lack of long-term strategy & See $[1,2,3,4]$ \\
2 & Lack of audit knowledge & See $[1,3,5]$ \\
3 & Confusing audit process & See $[1,3,6]$ \\
4 & No clear standards for performance audits & See $[2,3,4]$ \\
5 & Lack of adequate methodology and criteria for the audit process & See $[1,3,4,6]$ \\
6 & No current plans to introduce improved auditing processes & See $[7,8,9,10,11]$ \\
7 & Inconsistencies between audit process and auditing principles and standards & See $[2,3,12,13]$ \\
8 & Inappropriately and ineffectively driven system & See $[1,3,4,13,14]$, \\
\hline
\end{tabular}

The analysis of the current performance of the SAV shows that the SAV current auditing standards remain in an underdeveloped state. As the National Assembly Standing Committee of the Socialist Republic of Vietnam [4] states, the building of SAV auditing standards compatible with generally accepted international auditing standards is one of the crucial missions and responsibilities of the SAV mentioned in the SAV Development Strategy to the year 2020. In fact, the establishment of a strong auditing standard framework may positively contribute to audit quality and ensure the robustness and stability of public sector auditing $[15,16]$, and considerably reinforce public sector auditing so that it becomes an effective tool for government, economy and society $[1,4]$. It can be said that the SAV has not yet equipped and has insufficient capacity to develop strong auditing standards for its audit process fully compatible with the advanced countries' to realize its progressive ambition. Thus, the development of strong auditing standards is an urgent requirement of the SAV.

\subsection{Identifying the OECD Auditing Standards}

International auditing standards tend to be the most important driving force in changing the audit process of the SAV. As the Institute of Chartered Accountants in England and Wales [17] notes, generally accepted international auditing standards should be applied by the government audit institutions, and the formation and development of the audit process must work towards the goal of effectively enforcing auditing standards.

The OECD, which was founded in 1961 to enhance economic development and world trade [18], appears to be a good starting point to study and provide valuable information, experiences and models for shifting the SAV audit process. This organization consists of 35 member countries (including Australia), among which are the most economically advanced countries in the world [18]. The OECD auditing standards chosen as driving forces of the alternative audit process are identified as the goal that the SAV needs to achieve in order to improve its performance. The major feature of these standards is that they are strongly supported by technology and operated on a technologydriven system.

\subsection{Australian Government Audit Model - A Proposed Example for the Change Model}

Contrary to limitations and weaknesses in SAV audit process, the audit processes of the Australian Government audit offices are examples of best auditing practice in the developed world. An examination of the Nicoll document [19] discloses that the Australian Government audit offices, which have a history of more than 100 years of Parliamentary assurance, were established based on the strong auditing standards framework of a developed country. Thus, a study of Australia's audit process model focuses on Australian auditing standards that may be a good starting point in identifying the change model for the SAV current audit process. Based on the literature review, Table 2 illustrates major features which underline the strength of the Australian Government audit process.

Table 2. Major features which underline the strength of Australian Government audit process.

\begin{tabular}{lll}
\hline & $\begin{array}{l}\text { Major features which underline the strength of Australian Government audit } \\
\text { process }\end{array}$ & $\begin{array}{l}\text { Sources (Examination of documents that have been } \\
\text { contributed) }\end{array}$ \\
\hline 1 & High quality auditing practice & See $[16,19,20,21,22,23,24]$ \\
2 & High reliability of auditing results & See $[15,23,25]$ \\
3 & Effective macro-economic control & See $[19,26,27]$ \\
4 & High quality audit reporting system & See $[15,25,28,29,30]$ \\
5 & Minimised corruption and abuse of power & See $[15,25,29,31,32]$ \\
6 & High level of system stability & See $[15,19,25,27,33]$ \\
7 & Safe auditing information security & See $[25,27,33]$ \\
\hline
\end{tabular}

As Lombardi, Bloch, and Vasarhelyi [33] and McPhee [34] state, the audit system will achieve an optimal effectiveness with a combination of effective strong auditing standards and an auditing system driven by high-quality social forces. In contrast, conflict between international auditing standards and social forces appear likely to create potential weaknesses and limitations in the audit system. It is also worth noting that the Australian public sector auditing model may portray to some extent the characteristics of this senario. In fact, a combination of both strong auditing standards and competent harnessing of social forces has brought positive achievements in the quality and effectiveness of Australia Government 
public sector auditing $[15,19]$. It is clear that the Australian public sector auditing model, which represents the most advantageous and positive features of the change model of the SAV audit process, is likely to be regarded as a desirable change model.

However, it can be argued that the audit process of the SAV could be changed to become compatible with those of other advanced countries, of which the United Kingdom may be an ideal choice. In fact, as the Institute of Chartered Accountants in England and Wales [17] notes, United Kingdom auditing standards, which are regarded as strong and effective, cover and provide detailed guidance for all aspects of its audit activities and play an important role in ensuring and controlling audit quality, and the effectiveness of the audit activities substantially rely on the strict and compulsory compliance of these standards.

In addition, In the United States of America, the compulsory regularization required by the Sarbanes-Oxley Act in the audit field has had positive impacts on improving financial transparency and audit quality, promoting financial market stability and development [36]. Thus, the research is looking to improve the SAV to meet international auditing standards of the OECD, using the Australian Government audit process as a direct comparison.

\subsection{Literature Underpining the Evaluative Framework}

Motivated by the limitations in the SAV current performance, the research aims to contribute to the improvement of the SAV so as to meet the international audit standards of the OECD, using the Australian Government audit process as a direct comparison to identify changes needed. To implement those changes, it is necessary to establish an evaluative framework for the study. As discussed below, the change may face key challenges involving issues such as technology, people and costs. These issues can be significant factors identified in the evaluative framework.

Technology is increasingly becoming an important element that promotes and impacts change processes in organisations. The significance and impact of technology on all aspects of auditing activity worldwide is well recognized [34, 37, 38]. The application of IT in auditing is likely to enhance the effectiveness and quality of auditors' work by minimising problems such as errors, fraud and inconsistency in employing audit processes, procedures and methodologies caused by human auditors. The use of IT in auditing might enable public sector audit offices to reduce cycle times and to facilitate the implementation of audit engagements. This would increase the job satisfaction and productivity of auditors and audit staff.

However, application of IT in auditing might face with potential challenges. Application of IT to auditing requires improvements in the IT skills and knowledge of audit personnel [34]. The implementation of audit systems using IT significantly impacts audit methodology and quality control. Risks for IT errors arising from the changes from traditional audit to IT-supported audit may impact the quality and effectiveness of audit engagements [34, 37]. In addition,
IT security management and IT staff ethics pose significant challenges on the application of IT in auditing [39]. A study of a document of Moeller [14] indicates that information technology and application of IT to auditing involves several aspects: software, hardware, security and IT staff. All of these aspects need to be taken into account in relation to change management process required for the SAV audit process.

Futhermore, costs need to be considered in change management because change is required of utilizing considerable resources. An examination of the document of Lunenburg [40] indicates that in order to achieve an effective change management strategy, the goal of change needs be clarified to direct the activities and resources needed for the change management process. According to the British Educational Communications and Technology Agency [41], expenditure, people and time are considered as the main aspects of change management cost. Likewise, as Tran [24] notes, change process involving costs and risks is required for necessary resources, time and efforts. Costs involving the change management process can be categorised into IT, human resource, training, time and opportunity.

One of the most important factors of managing change is managing the human aspects of change. 'Managing the human aspects of change is frequently cited as one of the most significant factors to the 'success' or 'failure' of major change initiatives' (Pendlebury et al. 1998, cited in [42], p. 287). According to Myers, Hulks and Wiggins [43], human aspects of change such as psychology, culture, power, interests, politics, capacity and leadership, which have significant influence on organisational change, should be taken into account in change management processes. The human aspects involving the change management process can be categorised into psychological barriers to change, cultural barriers to change, knowledge and training, power and vested interests, government politics and leadership.

The evaluative framework is based on the following literature, identifying three major issues of concern (technology, people and costs). These issues are described as follows:

Technology: sofware, hardware, security and IT staff; people: psychological barriers to change, cultrual barriers to change, knowledge and training, power and vested interest, governement politics and leadership; costs: IT cost, human resource cost, training cost, time and opportunity cost and other relevant costs.

\section{Research Methodology}

This research applied Kotter's Eight Step Change Model to lead the change of the audit process of the State Audit Office of Vietnam to align with the Australian Government audit process. The research design is a combination of document review and semi-structured in-depth individual interview methods. Although research methodology focused on semistructured in-depth individual interviews, the document review was used to supplement the overall data. The goal of 
the document review was to obtain an overall picture of the research topic that will inform the in-depth interviews. In the study, 30 individual interviews were conducted for two groups of stakeholders (auditors and managers of the SAV) at the headquarters of the SAV in Hanoi City, the capital of Vietnam.

The data collected during the interviews was analysed in order to identify issues in change management processes. As the data includes various kinds of information and wide-ranging, overlapping and inconsistent thoughts, opinions and perspectives regarding the audit process and potential improvements to it, a data analysis methodology facilitating the extraction of key themes from the data was employed. Thematic content analysis (TCA), a popular data analysis methodology in qualitative research, was a suitable methodology because of its emphasis on the identification of themes or topics [44]. It allows researchers to assess and systematize the data gathered from interview transcriptions [45], and was therefore selected for the data analysis of the study.

\section{Data Collection and Analysis}

\subsection{Data Collection}

In the study, 30 individual interviews were conducted for two groups of stakeholders (the SAV auditors and managers). The SAV auditors and managers selected to participate in the individual interviews worked for the various specialized Audit Departments of the Headquarters of the SAV in Hanoi. A diversity of SAV experience, education backgrounds, professional experience and knowledge and positions were represented. The participants displayed significant variety in terms of education background with qualifications including Bachelor, Master and Doctor Degrees. Most participants were highly educated with a diversity of professional experience and knowledge. The majority of participants serving in manager position had over 5 years' experience with auditing work. In order to compare the ideas of experienced and new auditors, two of the auditors selected for the interviews were in the probation period.

The following procedure for thematic content analysis was followed during analysis phase. It is based on the procedure outlined by Newell and Burnard [45].

Phase one: writing down memos for interviews; phase two: scrutinizing interviews transcripts and forming overall themes; phase three: intensive reading and establishing open coding headings to portray all perspectives of the data collected; phase four: developing a shorter and more representative and controllable set of themed headings; phase five: restudying the data equipped with the reduced list of themed headings.

\subsection{Data Analysis}

After interviews, the interview transcripts were analysed by thematic content analysis method. The six themes were identified and extracted in the findings of the analysis of the interview transcripts. The themes have emerged from the examination process. They include personal issues in relation to change, cultural barriers to change, technological barriers to change, costs for the change, obstacles to change arising from limitations and weaknesses in the SAV auditor human resource quality and auditor training, and the SAV organisational and operational model in relation to the change.

\section{Discussion of Research Findings}

In this section, the research findings detail discussions with reference to relevant documents identified by the document review. The research findings extracted from the outcomes of the interview analysis and supplemented from the literature review identified issues in the change management processes. The research findings organised into six themes can be presented as follows:

Theme 1: Personal issues in relation to the change

Stakeholders may not be aware or have a positive attitude about the change; the change may have negative influences on stakeholders' or groups' power and interests; issues arising from stakeholders' individual personality and habits may be encountered in the change process; stakeholders' poor experience in implementing organizational changes, tensions and personal inertia may negatively impact on the implementation of the change.

Theme 2: Cultural barriers to change

Working style: Professional experiences are emphasized in the SAV culture. In contrast, professionalism, critical and innovative thinking are emphasized in the culture of the government audit offices of the OECD member countries; time: conception of time is understood as relative and changeable in the SAV culture. In contrast, conception of time is understood as exact and absolute in the culture of government audit offices of the OECD member countries; work and life balance: balance between personal issues and work and building a family-like work environment are emphasized in the SAV culture. In contrast, effectiveness and independence are emphasized and work is put in the first position in the culture of government audit offices of the OECD member countries; auditing methodology: SAV auditors' traditional auditing methodology is based on experience, manual working, fieldwork, note takings, and direct interviews and observation in the SAV culture. In contrast, auditing methodology of government audit offices of the OECD member countries is based on specialized audit software programs and technology-driven system.

Theme 3: Technological barriers to change

The SAV lacks of high-quality software programs for the implementation of the change; the SAV IT hardware and electronic database system has been underdeveloped; the SAV current network system has not met the requirement of developing a strong network system connecting the SAV with entities being audited and other relevant organizations; the SAV has not applied technological advances in order to effectively safeguard its IT security; IT risks may arise from stakeholders' poor IT knowledge and skills and improper IT managerial methodology; quantity and quality of the SAV IT 
human resource does not correspond with requirements of development of the SAV and the change. IT training programs for the SAV IT staff have not been developed.

Theme 4: Costs for the change

Costs for improving the SAV headquarters, IT hardware and software, facilities, equipments and maintenance; costs for salaries, bonuses and executive compensation and training; costs for legal documents and workshops in relation to improvements of legal documents; costs for international cooperation, time cost and opportunity cost; the SAV may not afford enough financial resources for the implementation of the change; global financial crisis has indirect influence on the implementation of the change.

Theme 5: Obstacles to change arising from limitations and weaknesses in the SAV auditor human resources quality and auditor training

Multiple auditors of the SAV have not enough competence and qualification to implement the change and do not appreciate the role of auditing standards; multiple auditors of the SAV have been trained in specialisations different from auditing and are not proficient in IT and foreign languages.

Short duration of the training programs conflicts with the high volume of provided knowledge; the SAV auditors have no right to choose alternative or necessary subjects in the SAV auditor training programs; the SAV training programs are not designed to integrate into internationally recognised auditor training programs; the SAV lacks practical skills training programs and qualified lecturers and has not emphasised performance and IT auditing and application of IT for auditing in its auditor training programs; the SAV auditor certificate has not been internationally recognised; indirect influences on the SAV auditor training include frequent changes in the SAV personnel, long duration of SAV audit engagements (nine months per year) and the SAV undeveloped IT infrastructure.

Theme 6: The SAV organisational and operational model in relation to the change

The SAV legal documents have been inadequate and inconsistent; the SAV has not established a strong legal framework for development of performance and IT auditing; legitimacy of the SAV electronic signatures, electronic documents and electronic evidences are weak and no great emphasis is placed on them; the SAV organizational apparatus has not been comprehensively developed.

\section{Recommendations}

The key issues in the change management processes have been discussed and clarified. These issues have been identified from the literature review, the analysis of interview transcripts and the consultation workshops which have contributed to developing a strategic model to change the audit process of the SAV. Figure 1 demonstrates the recommendation formation process for the strategic model to change the audit process of the SAV.

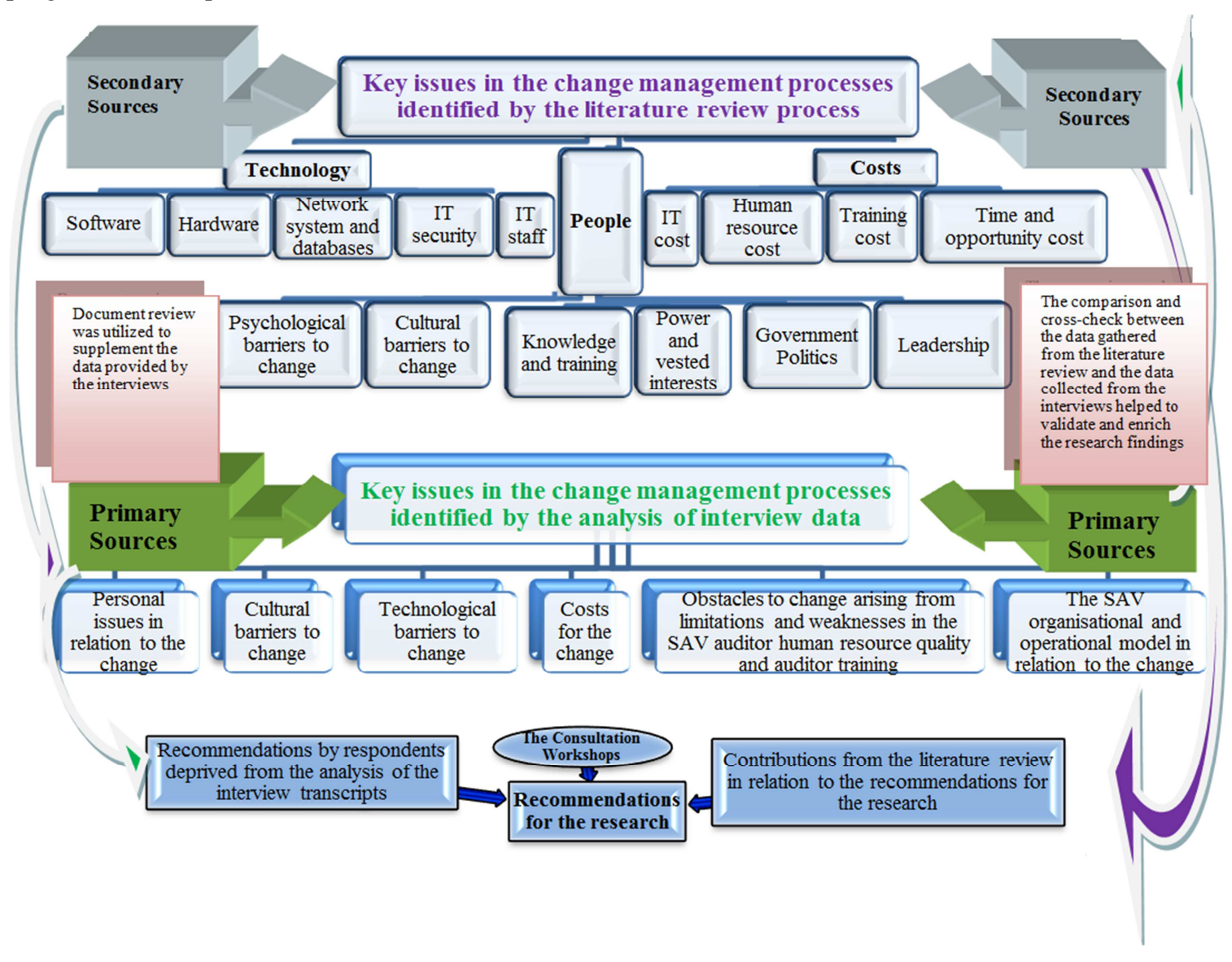

Figure 1. The recommendation formation process for the strategic change model. 
Based on suggestions and recommendations by participants and contributions acquired through the literature review and the consultation workshops, policy recommendations for developing a strategic model to change the audit process of the SAV have been employed. This recommended strategic model addresses the key issues in the change management processes discussed above. The recommended strategic model is presented in Figure 2.

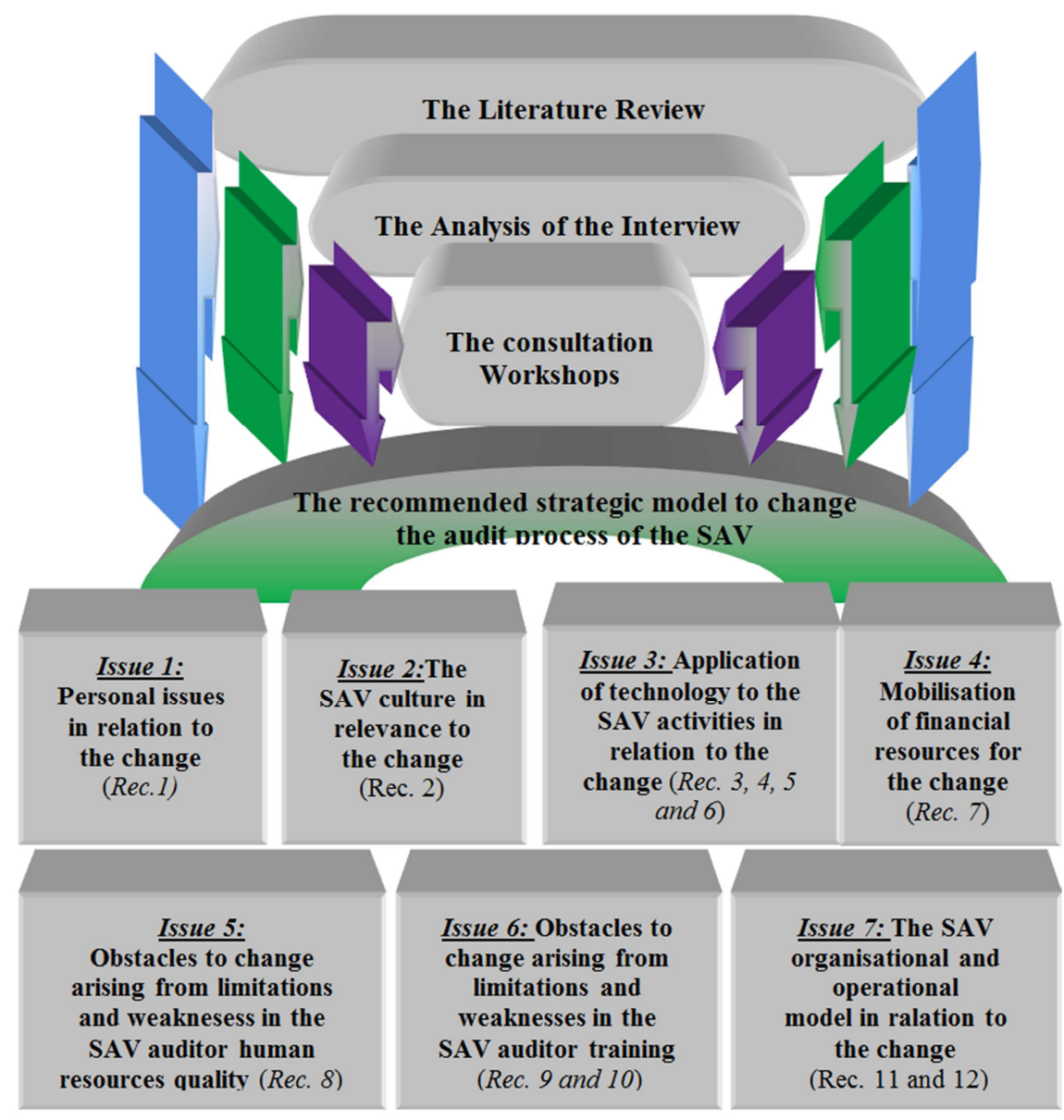

Figure 2. Recommended strategic model to change the audit process.

The following are the policy recommendations corresponding to the seven key themes identified in the strategic model above.

Personal issues in relation to the change

Recommendation 1: It is recommended that the SAV should strengthen information dissemination towards the change and leadership of the change leaders.

The SAV culture in relevance to the change

Recommendation 2: It is recommended that the SAV should anchor new cultural changes into SAV culture, these changes include: computerized work environment, computer assisted audit methodology, up-to-date audit equipments, deployment of the SAV IT teams and improvements in professionalism of the SAV auditors and transparency of the SAV audit information.

Application of technology to the SAV activities in relation to the change

Recommendation 3: It is recommended that the SAV should apply safe and up-to-date IT software programs to all its activities and adequately provide appropriate and effective IT devices to its employees.

Recommendation 4: It is recommended that the SAV should improve its IT devices and databases for auditing, and develop a strong electronic database system.

Recommendation 5: It is recommended that the SAV should build a common and integrated network system connected from the SAV to entities being audited and other relevant organizations.

Recommendation 6: It is recommended that the SAV should improve its IT human resource quality and provide its IT staff with advanced IT training programs.

Mobilisation of financial resources for the change

Recommendation 7: It is recommended that the SAV should ask for financial support regarding the implementation of the change from the Vietnam Government, international and Vietnamese development support funds, financial institutions and international auditing organizations and other organizations.

Obstacles to change arising from limitations and weaknesses in the SAV auditor human resources quality

Recommendation 8: It is recommended that the SAV should establish a strategy to develop a professional auditor and a detailed human resource quality valuation framework and improve IT knowledge and skills and foreign language 
competence for SAV auditors.

Obstacles to change arising from limitations and weaknesses in the SAV auditor training

Recommendation 9: It is recommended that the SAV should classify its auditors into appropriate auditor training programs, design SAV auditor training programs associating theories with practices, replace periodical training with regular training and develop handbooks and manuals about the OECD auditing standards.

Recommendation 10: It is recommended that the SAV should strengthen training performance and IT audits for its auditors, develop professional lecturers and researchers and enhance international cooperation in auditor training and education.

The SAV organisational and operational model in relation to the change

Recommendation 11: It is recommended that the Vietnam Government and the NARSV should build strict and clear guidelines and policies in relation to the development of the SAV IT infrastructure; application of IT to the SAV audit activities, the SAV legal framework and mobilisation and utilisation of resources needed for the change.

Recommendation 12: It is recommended that the SAV should establish strong policies and regulations related to its IT human resource management, IT management, network system, electronic database system and IT security.

\subsection{A Policy Proposal for the SAV in Changing Its Audit Process}

Although this research might be applied to the SAV, its effectiveness will be strengthened if the SAV obtains a high degree of unanimity and cooperation of the Vietnam Government and the NASRV, entities being audited and other relevant organisations. The research suggests a policy proposal for the SAV in shifting its audit process. The SAV should:

Widen its sample size, include more issues and increase the number of SAV Regional Offices participating in the research problem; conduct further studies about issues discussed in the research, especially insist on studying complex aspects of the research such as government politics and the SAV culture; conduct more discussions and communications with stakeholders about the change; apply the recommended strategic model to change the audit process of the SAV discussed in this paper. This process was to resolve issues arising from the change management processes required for the SAV to introduce the Australian Government audit process.

\subsection{Implications and Limitations}

The first implication of the research is that the SAV should improve its legal framework. These changes facilitate not only the implementation of the OECD auditing standards but also development of the SAV. In addition, the research implies that the SAV needs to improve its human resources quality and training programs. English language and computing competence of the SAV staff members need to be improved. SAV training programs need to be balanced between theory and practice and widened to encompass strong auditing standards such as performance and IT audit standards. In respect of IT infrastructure, the SAV should improve its IT software, hardware and security and network systems in order to facilitate its auditors in implementing IT audits. The SAV staff members should be adequately and appropriately trained with IT knowledge and skills and provided with professional audit software programs. The SAV needs to improve awareness, knowledge and responsibility of the SAV staff members on IT security and apply modern and up-to-date IT security solutions to safeguard its IT system.

However, the research also has several limitations. First, the research did not include quantitative methodologies. Both semi-structured in-depth individual interviews and document review, which are data collection methodologies of the study, are qualitative methodologies. Second, the context of the research is only limited to the headquarters of the SAV in Hanoi City, Vietnam. Third, there is a relatively small number of auditors and managers of the SAV participating in the study. Fourth, the issues arising from the analysis of the interview data involves a wide range of disciplines. The context that the document review focused on is the SAV. Fifth, while there are numerous issues needing to be discussed, timing of interviewing, which is restricted, impacts on the quality of interviews. Finally, although respondents acknowledged that anonymity and confidentiality was guaranteed, the researcher feels that several respondents seemed to avoid straight criticism and discussion about sensitive issues such as political and cultural issues. This might be due to the influence of occupational cautiousness or the personal character of these respondents.

\section{Conclusion}

The current audit process of the SAV is inadequate in several ways. This may have a negative influence on the quality and effectiveness of the current performance of the SAV. Changing the SAV audit process is thus a strategy that has the potential to contribute significantly to the SAV development. The paper was looking to improve the SAV to meet the international audit standards of the OECD. It use the Australian Government audit process as a direct comparison in order to identify issues in the change management processes required for the SAV to introduce Australian Government audit processes and to propose a methodology to resolve these issues.

To change the SAV audit process, the study has employed the literature review and a combination of document reviews and semi-structured in-depth individual interviews. In the study, 30 individual interviews were conducted for two groups of stakeholders (auditors and managers of the SAV at the headquarters of the SAV in Hanoi City, the capital of Vietnam). The research data collected by semi-structured indepth individual interviews was analyzed using TCA. The 
analysis of the interview transcripts revealed issues requiring clarification. Documents identified by document reviews were used to clarify the issues arising from the analysis of the interview data.

The research findings synthesized by outcomes of the interview and document analysis identified key issues in the change management process. These issues involved stakeholders awareness, their emotions, personality, habits, power and interests and the SAV culture. It also included IT infrastructure, legal framework, human resources and training, costs for the change and necessary co-operation.

The research findings extracted from the outcomes of interview analysis identified issues in the change management processes. Based on the literature review, the analysis of the interview data and the consultation workshops, the strategic model to change the audit process of the SAV were recommended. The research results found that the SAV should enhance the information dissemination of the change and provide timely, adequate and reliable information about the change to all stakeholders in order to dispel their worries and misunderstandings about the change. It is noted that the change will be effectively implemented if it is developed with a clear vision and supported by change leaders having strong leadership. In addition, the SAV should focus on improving its infrastructure, auditor human resources, auditor training quality and legal framework in order to meet with requirements of its development and change. Embedding changes into the SAV culture should be employed in order to ensure changes to become an integral part of the SAV.

\section{References}

[1] State Audit Office of Vietnam. (2013). The action plan to implement the SAV's development strategy for the period 2013 - 2017. Hanoi, VN: Author.

[2] National Assembly of the Socialist Republic of Vietnam. (2015). The State Audit Law 2015 of Vietnam. Hanoi, VN: Author.

[3] State Audit Office of Vietnam. (2016a). The Auditing Process of the State Audit Office of Vietnam. Hanoi, VN: Author.

[4] National Assembly Standing Committee of the Socialist Republic of Vietnam. (2010). The SAV's Development Strategy to the year 2020. Hanoi, VN: Author.

[5] International Organisation of Supreme Audit Institutions. (2016). ISSAI 5000: Audit of International Institutions Guidance for Supreme Audit Institutions (SAIs). Copenhagen, DK: Author.

[6] Ngo, V. N. (2008). The improvement of the organizational and operational model of the State Audit Office of Vietnam (Unpublished doctoral dissertation). National Library of Vietnam, Hanoi, VN.

[7] State Audit Office of Vietnam. (2017a). The Audit Process for financial institutions and banks. Hanoi, VN: Author.

[8] State Audit Office of Vietnam. (2017b). The Audit Process for state-owned enterprises. Hanoi, VN: Author.

[9] State Audit Office of Vietnam. (2017c). The Audit Process for Construction Projects. Hanoi, VN: Author.

[10] State Audit Office of Vietnam. (2017d). The Audit Process for Targeted National Programs. Hanoi, VN: Author.

[11] State Audit Office of Vietnam. (2017e). The Audit Process for the State Budget. Hanoi, VN: Author.

[12] State Audit Office of Vietnam. (2016b). The Auditing Quality Control Regulations of the State Audit Office of Vietnam. Hanoi, VN: Author.

[13] State Audit Office of Vietnam. (2016c). The Auditing Standards of the State Audit Office of Vietnam. Hanoi, VN: Author.

[14] Moeller, R. (2010). IT Audit, Control and Security. New Jersey, NE: John Willey \& Sons.

[15] The Treasury of Australian Government. (2010). Audit quality in Australia: Strategic Review. Canberra, AU: Author.

[16] Arens, A. A., Best, P. J., Shailer, G. E. P., Fiedler, B. A., Elder, R., and Beasley, M. (2017). Auditing, Assurance Services \& Ethics in Australia: An integrated approach (10th ed.). Melbourne, AU: Pearson.

[17] Institute of Chartered Accountants in England and Wales. (2016). Knowledge guide to UK Auditing Standards. London, UK: Author.

[18] Organization for Economic Co-operation and Development. (2018). Secretary-General's Report to Ministers 2018. Paris, PR: Author.

[19] Nicoll, P. (2016). Audit in a Democracy: The Australian Model of Public Sector Audit And Its Application to Emerging Markets. Uxbridge, UK: Routledge.

[20] Australian Auditing and Assurance Standards Board. (2018). Australian Auditing Standards. Melbourne, AU: Author.

[21] Australian Auditing and Assurance Standards Board. (2017c). Auditing Standard ASA 800: Special Considerations - Audits of Financial Reports Prepared in Accordance with Special Purpose Frameworks. Melbourne, AU: Author.

[22] Australian National Audit Office. (2017). The AuditorGeneral Annual Report 2016-2017. Canberra, AU: Author.

[23] Dahanayake, S. J. (2007). Public Sector Auditing: The Australian experience. Institute of Chartered Accountants of Sri Lanka, 42 (2), 9-14.

[24] Tran, V. N. (2011, March). Managing Organizational Change from the Middle. Paper presented at the ACMP Global Conference, Orlando, FL.

[25] Hehir, G. (2017, December). The challenges of achieving quality in a standards-based approach to auditing in the public sector. Paper presented at the Australian National Centre for Audit And Assurance Research (ANCAAR) $15^{\text {th }}$ ANCAAR Audit Research Forum, Canberra, AU.

[26] McPhee, I. (2011, October). The evolving role and mandate of the Australian National Audit Office since federation. Senate Occasional Lecture presented at the Parliament House, Canberra, AU. 
[27] Australian National Audit Office. (2018b). ANAO Risk Management Framework 2017-18. Canberra, AU: Author.

[28] Australian Auditing and Assurance Standards Board. (2017b). Auditing Standard ASA 450: Evaluation of Misstatements Identified during the audit. Melbourne, AU: Author.

[29] Australian Auditing and Assurance Standards Board. (2017a). Auditing Standard ASA 240: the auditor's responsibility to consider fraud in an audit of financial report. Melbourne, AU: Author.

[30] Carson, E., Fargher, N., and Zhang, Y. (2017). Trends in auditor reporting in Australia: a synthesis and opportunities for research. Australian Accounting Review, 26 (3), 226-242.

[31] Australian National Audit Office. (2010). Fraud control in Australian government agencies. Canberra, AU: Author.

[32] Australian National Audit Office. (2018a). ANAO 2017-18 Corporate Plan. Canberra, AU: Author.

[33] Glynn, K., Ben, B., and Chartered Accountants Australia and New Zealand. (2017). Australian Audit Manual and Toolkit 2017: Small and Medium Sized Entities (7th ed.). New South Wales, AU: Thomson Reuters (Professional) Australia Limited.

[34] Lombardi, D., Bloch, R., and Vasarhelyi, M. (2014). The Future of Audit. Journal of Information Systems and Technology Management. 11, 21-32.

[35] McPhee, I. (2011, October). The evolving role and mandate of the Australian National Audit Office since federation. Senate Occasional Lecture presented at the Parliament House, Canberra, AU.

[36] United States Government Accountability Office. (2006).
Sarbanes-Oxley Act: Consideration of Key Principles needed in addressing Implementation for Smaller Public Companies. Washington, DC: Author.

[37] Sah, N. K. (2016). Leveraging Technology for enhancing Public Audit. Asian Journal of Government Audit, October 2016, 10-18.

[38] Mustapha, M., and Lai, S. J. (2017). Information Technology in Audit Processes: An Empirical Evidence from Malaysian Audit Firms. International Review of Management and Marketing, 7, 53-59.

[39] Information Systems Audit and Control Association. (2013). IT Audit and Assurance Standards and Guidelines. Schaumburg, IL: Author.

[40] Lunenburg, F. C. (2010). Approaches to Managing Organizational Change. International Journal of Scholarly Academic Intellectual Diversity, 12 (1), 1-10.

[41] British Educational Communications and Technology Agency. (2004). Change management. Coventry, UK: Author.

[42] Andriopoulos, C., and Dawson, P. (2009). Managing Change, Creativity \& Innovation. London, UK: Sage.

[43] Myers, P., Hulks, S., and Wiggins, L. (2012). Organizational Change: Perspectives on Theory and Practice. Hampshire, UK: Ashford.

[44] Burnard, P., Gill, P., Stewart, K., Treasure, E., and Chadwick, B. (2008). Analysing and presenting qualitative data. Bristish Dental Journal, 204, 429-432.

[45] Newell, R., and Burnard, P. (2006). Research for EvidenceBased Practice. Oxford, UK: Blackwell. 